\title{
Role of Silicon in Quenching and Partitioning Treatment of Low- carbon Martensitic Stainless Steel
}

\author{
Junya TOBATA, Kinh-Luan NGO-HUYNH, Nobuo NAKADA, Toshihiro TSUCHIYAMA and Setsuo TAKAKI \\ Graduate Student, Graduate School of Engineering, Kyushu University, 744 Motooka, Nishi-Ku, Fukuoka, $819-0395$ Japan. E- \\ mail: tobata10@takaki.zaiko.kyushu-u.ac.jp
}

(Received on March 2, 2012; accepted on March 21, 2012)

\begin{abstract}
Quenching and partitioning (Q\&P) treatment was applied to $12 \% \mathrm{Cr}$ low-carbon martensitic stainless steels containing different amount of silicon, and then the effect of silicon content on the formation of retained austenite was discussed in terms of the behaviors of phase transformation and carbide precipitation during the partitioning treatment. It was suggested that the nearly ideal constrained carbon equilibrium (CCE) condition was realized in the specimens used in this study because a large amount of chromium suppressed bainitic transformation during the partitioning treatment, although cementite was partly observed at the retained austenite/martensite interface. The cementite precipitation was greatly retarded with increasing silicon content, resulting in an increase in the amount of retained austenite and an enhancement of the thermal stability of austenite. Tensile testing for the Q\&P-treated specimens revealed that the increment of silicon content leads to a marked improvement of strength-ductility balance of the $12 \% \mathrm{Cr}$ steels through the increase of retained austenite.
\end{abstract}

KEY WORDS: Q\&P; martensitic stainless steel; retained austenite; silicon; constrained carbon equilibrium; TRIP effect.

\section{Introduction}

Martensitic stainless steels are applied to various machine parts in a mild corrosive environment because they possess higher strength and wear-resistance as compared to other stainless steels. However, their toughness and ductility are insufficient for the structural use. Although the mechanical properties of martensitic stainless steels can be controlled by the condition of tempering, ${ }^{1,2)}$ it is difficult to improve both of strength and ductility simultaneously by conventional tempering treatment due to the trade-off relationship between them. ${ }^{3)}$

On the other hand, in the case of high-strength low-alloy steel (HSLA) applied to automobile, it is well-known that retained austenite can increase toughness and ductility without losing high strength owing to the transformation induced plasticity (TRIP) effect. ${ }^{4-7)}$ Austempering to form carbidefree bainite ${ }^{4,7)}$ and quenching and partitioning (Q\&P) treatment ${ }^{8,9)}$ are utilized to make sufficient amount of retained austenite disperse within matrix. In relation to such a technical development, authors have recently proved that the Q\&P treatment is also available for low-carbon martensitic stainless steel $\left(12 \mathrm{Cr}-0.12 \mathrm{C}-0.26 \mathrm{Si}-0.87 \mathrm{Mn}^{*}\right.$ steel $){ }^{10}{ }^{0}$ As a result of Q\&P treatment for the steel, more than $10 \%$ of retained austenite was obtained and its strength-ductility balance was significantly improved.

The Q\&P treatment of martensitic stainless steel, however, has some unclear phenomena peculiar to this kind of steel. One of them is the kinetics of the carbide precipitation during partitioning treatment. In the conventional Q\&P treatment for low-alloy TRIP steels, fairly large amount of silicon $(>1.0 \%)$ must be added to suppress cementite precipitation so as not to deteriorate the stability of retained austenite, ${ }^{11,12)}$ while the Q\&P-treated martensitic stainless steels produced in the previous study contained less silicon content $(0.26 \%)$. Thus, the authors concluded that silicon is not necessarily required for forming retained austenite by Q\&P in the case of martensitic stainless steel. ${ }^{10)}$ However, it is likely that silicon addition would give some influence on the kinetics of carbide precipitation and also on the amount of retained austenite in martensitic stainless steel, because cementite $\left(\mathrm{M}_{3} \mathrm{C}\right)$ can be formed even in $12 \mathrm{Cr}$ steel just like the case of low-alloy steels. ${ }^{13)}$ To develop the Q\&P process for martensitic stainless steels, it must be quantitatively assessed whether the silicon addition affects the carbide precipitation kinetics and stability of austenite or not.

The purpose of this study is to clarify the role of silicon in Q\&P treatment of low-carbon martensitic stainless steels, by using the type 410 steel containing different amount of silicon. The change of microstructure with Q\&P treatment was discussed in terms of the stability of retained austenite and the behavior of carbide precipitation. Besides, mechanical properties were also examined by tensile testing in order to make the role of retained austenite clear in the low-carbon martensitic stainless steels.

*Throughout this article, the chemical composition is expressed in mass percent, unless otherwise stated. 


\section{Experimental Procedure}

Three kinds of martensitic stainless steels (type 410) with different silicon content were prepared in this study. The chemical compositions of the steels used are listed in Table 1. The ingots produced by induction melting in a vacuum were hot-rolled at $1473 \mathrm{~K}$ to $16 \mathrm{~mm}$ in thickness. Specimens cut from the hot-rolled plate were subjected to the heat treatment shown in Fig. 1. The specimens were firstly austenitized at $1273 \mathrm{~K}$ for $3.6 \mathrm{ks}$ and then quenched to a 'quench interruption temperature (QT)' between $\mathrm{Ms}$ and $\mathrm{Mf}$ temperature (quenching treatment). After the $0.06 \mathrm{ks}$ holding at QT, the specimens were reheated and held at $723 \mathrm{~K}$ for $0.06 \mathrm{ks}$ to 100 ks (partitioning treatment), followed by water-cooling to room temperature. The optimum QT for forming the largest amount of retained austenite was selected for each specimen by taking the silicon content into consideration, as explained later. The Ms and Mf temperature and the transformation rate during partitioning treatment were evaluated by thermal dilatation tester equipped with a temperature control system, where cylindrical test pieces of $\phi 5 \times 4 \mathrm{~mm}$ were used for the measurement of Ms and Mf, and bar test pieces of $4 \mathrm{~mm} \times 4$ $\mathrm{mm} \times 10 \mathrm{~mm}$ were done for transformation rate.

Microstructures of the Q\&P-treated samples were examined by means of optical microscopy (OM), electron back scattered diffraction pattern analysis with a field emission scanning electron microscope (EBSD/FE-SEM) and transmission electron microscopy (TEM). For the OM microstructural observation, the specimens were polished mechanically, and then etched by $3 \%$ of picric acid with a few drops of hydrochloric acid. The thin foils for EBSD and TEM observation were made by electrical jet-polishing in solutions of $10 \%$ perchloric acid and $90 \%$ acetic acid at room temperature. The data obtained by the EBSP was analyzed with the TSL Orientation Imaging Microscopy (OIM) system. The volume fraction of retained austenite, $f$, was estimated from the ratio of saturation magnetization between the measured value $I$ and the standard one $(12 \mathrm{Cr}-$ $0.12 \mathrm{C}$ ferritic steel), $I_{s}$, with Eqs. (1) and (2): ${ }^{14)}$

$$
f[\mathrm{vol} \%]=\left(1-I / I_{S}\right) \times 100 \ldots
$$

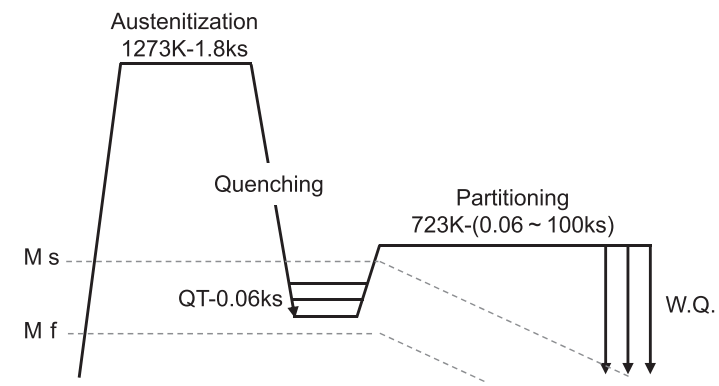

Fig. 1. Quenching and partitioning (Q\&P) process.

$$
\begin{aligned}
& I_{S}=2.14-0.030([\% \mathrm{Cr}]+1.8[\% \mathrm{Si}] \\
& +0.9[\% \mathrm{Mn}]+3.6[\% \mathrm{C}])
\end{aligned}
$$

X-ray diffractometry was also used to measure the lattice parameters of the samples, where the thin plate specimens with a dimension of $10 \mathrm{~mm} \times 10 \mathrm{~mm} \times 1 \mathrm{~mm}$ were used.

The mechanical properties of the Q\&P-treated specimens were evaluated by tensile tests using an Instron-type testing machine at a strain rate of $3.3 \times 10^{-3} \mathrm{~mm} / \mathrm{s}$ for the plate specimens with a gauge dimension of $3 \mathrm{~mm} \times 6 \mathrm{~mm} \times 1 \mathrm{~mm}$.

\section{Results and Discussion}

\subsection{Optimization of Quench Interruption Tempera- ture}

In order to maximize the amount of retained austenite by Q\&P treatment, the carbon concentration in untransformed austenite should be enriched after partitioning to have Ms temperature below room temperature. ${ }^{8,9)}$ The Ms temperature of $12 \mathrm{Cr}-\mathrm{C}$ steel was formulated as a function of carbon content in the previous study, ${ }^{10)}$ and besides, the effect of silicon addition was found as $(-8 \mathrm{~K} / \% \mathrm{Si})$ by dilatometry in this study. As a result, an empirical equation giving Ms temperature was obtained as follows for $12 \mathrm{Cr}-\mathrm{Si}-\mathrm{C}$ steels:

$$
\text { Ms }[\mathrm{K}]=652-510(\% \mathrm{C})-8(\% \mathrm{Si})
$$

According to the Eq. (3), it is predicted for $12 \mathrm{Cr}$ steels that carbon must be enriched to approximately $0.7 \%$ to lower the Ms temperature to room temperature, under the assumption that the constrained carbon equilibrium $(\mathrm{CCE})^{8,9,15,16)}$ holds during the partitioning treatment. Since the specimens used in this study contain approximately $0.12 \%$ of carbon, a sixfold enrichment is needed to reach $0.7 \%$, thus, the volume fraction of untransformed austenite must be reduced to approximately 17 vol $\%$ after the interrupted quenching. The quench interruption temperature can be determined by using thermal dilatation curve. For example, Fig. 2 displays a thermal dilatation curve of the $0.2 \mathrm{Si}$ steel showing martensitic transformation on cooling. In this case, the quench interruption temperature is determined at $513 \mathrm{~K}$. Likewise, the quench interruption temperature was determined for all specimens. They are plotted as a function of silicon content together with the Ms and Mf temperatures in Fig. 3. The optimum quench interruption temperature decreases with an increase of silicon but the change by $1 \%$ silicon addition is only $8 \mathrm{~K}$.

\subsection{Microstructure Obtained by $Q \& P$ Treatment}

After the interrupted quenching at the optimum temperature (QT) given in Fig. 3, partitioning treatment was performed equally at $723 \mathrm{~K}$ for all specimens. This partitioning temperature was determined for $12 \mathrm{Cr}$ steels in the previous study to maximize the amount of austenite in a moderate treatment time $(0.6 \mathrm{ks}){ }^{10)}$ Figure 4 shows the change in vol-

Table 1. Chemical compositions of steels used in this study (mass\%).

\begin{tabular}{ccccccccccc}
\hline steel & $\mathrm{C}$ & $\mathrm{Si}$ & $\mathrm{Mn}$ & $\mathrm{P}$ & $\mathrm{S}$ & $\mathrm{Ni}$ & $\mathrm{Cr}$ & $\mathrm{N}$ & $\mathrm{O}$ & $\mathrm{Al}$ \\
\hline 0Si steel & 0.129 & $<0.01$ & 0.82 & 0.034 & 0.0053 & 0.01 & 12.05 & 0.0085 & 0.0114 & $<0.001$ \\
0.2Si steel & 0.120 & 0.21 & 0.83 & 0.034 & 0.0053 & 0.01 & 12.13 & 0.0080 & 0.0110 & $<0.001$ \\
1Si steel & 0.123 & 0.94 & 0.85 & 0.032 & 0.0052 & 0.01 & 12.12 & 0.0084 & 0.0054 & $<0.002$ \\
\hline
\end{tabular}


ume fraction of retained austenite in Q\&P-treated specimens as a function of partitioning time. Although no retained austenite exists in the specimens directly quenched to room temperature (as-quenched), the volume fraction of retained austenite is markedly increased with increasing partitioning time and reaches to a maximum, and then decreased again after long-time treatment. It is clearly demonstrated here

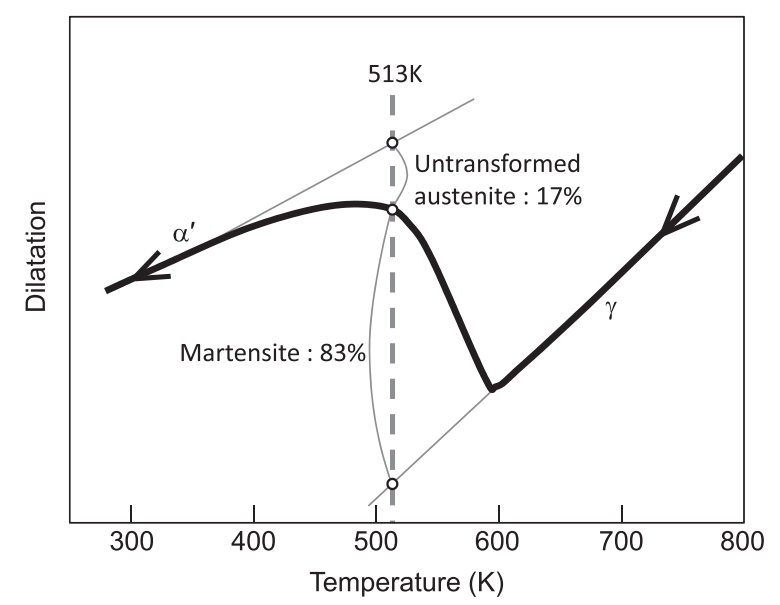

Fig. 2. Dilatometric curve around the martensitic transformation temperature showing the optimum quenching temperature for Q\&P treatment of $12 \mathrm{Cr}-0.12 \mathrm{C}-0.2 \mathrm{Si}$ steel.

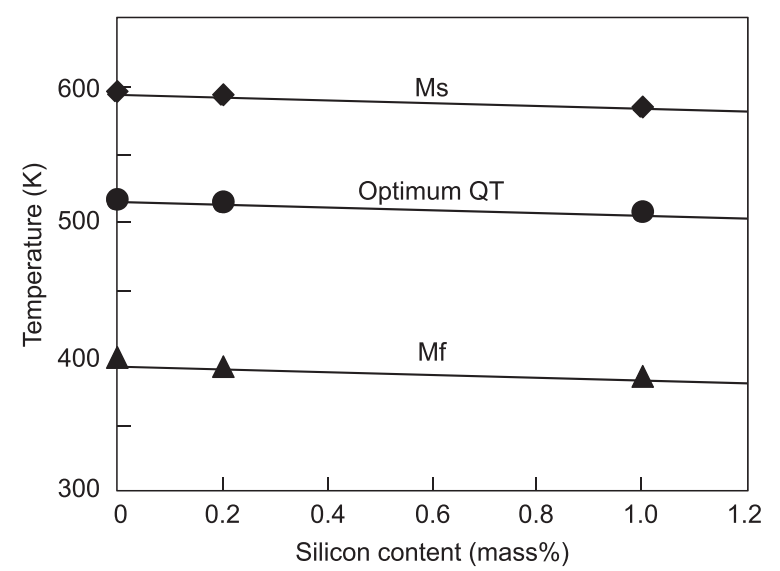

Fig. 3. Change in Ms temperature, Mf temperature and the optimum quench interruption temperature (QT) as a function of silicon content.

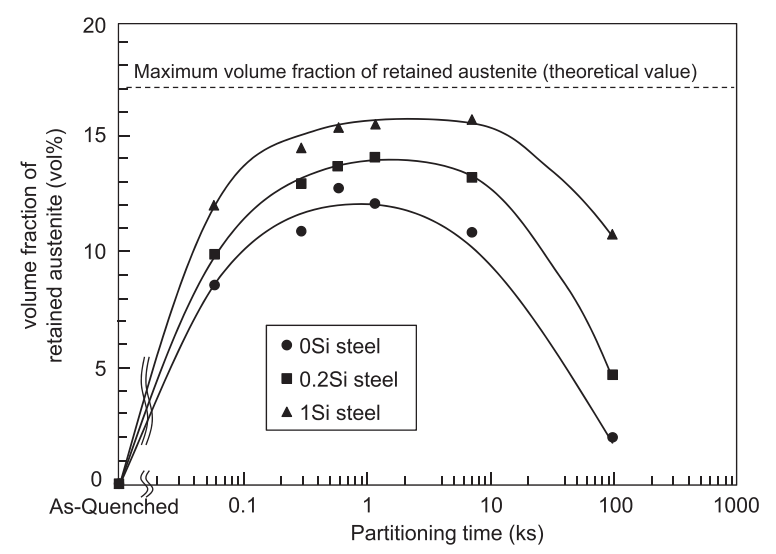

Fig. 4. Change in volume fraction of retained austenite as a function of partitioning time at partitioning temperature of 723 $\mathrm{K}$ in $12 \mathrm{Cr}-0.12 \mathrm{C}-\mathrm{Si}$ steels. that the addition of silicon promotes the formation of retained austenite. However, even in $1 \mathrm{Si}$ steel, the amount of retained austenite does not reach the ideal fraction of 17 vol\% in any condition. On the other hand, the time to reach the maximum volume fraction tends to shift to longer side as silicon content increases. This means that silicon addition contributes to the enhancement of the stability of retained austenite. Accordingly, after the long-time treatment of 100 $\mathrm{ks}$, more than $10 \mathrm{vol} \%$ of retained austenite can exist in $1 \mathrm{Si}$ steel, but less than $5 \mathrm{vol} \%$ of austenite remains in 0Si and $0.2 \mathrm{Si}$ steel.

Figure 5 shows the orientation imaging maps of the 0.6 ks partition-treated specimens in which the volume fraction of retained austenite has reached the maximum values. Martensite (bcc phase) and retained austenite (fcc phase) are simultaneously shown in the maps $(a)(c)(e)$, while only retained austenite is shown in the maps (b)(d)(f). The bold lines (black and white) and broken lines (white) drawn prior austenite grain boundaries and the prior annealing twin boundaries, respectively. It was confirmed that the twin relationship exists between the retained austenite grains neighboring across the annealing twin boundaries. As seen in this figure, all the specimen exhibit similar lath martensitic structure composed of packet and blocks, and there is little difference in the size and morphology of the structure among the specimens. Furthermore, it is found that very small retained austenite grains homogeneously disperse in the martensite matrix and exist at the boundaries of blocks,

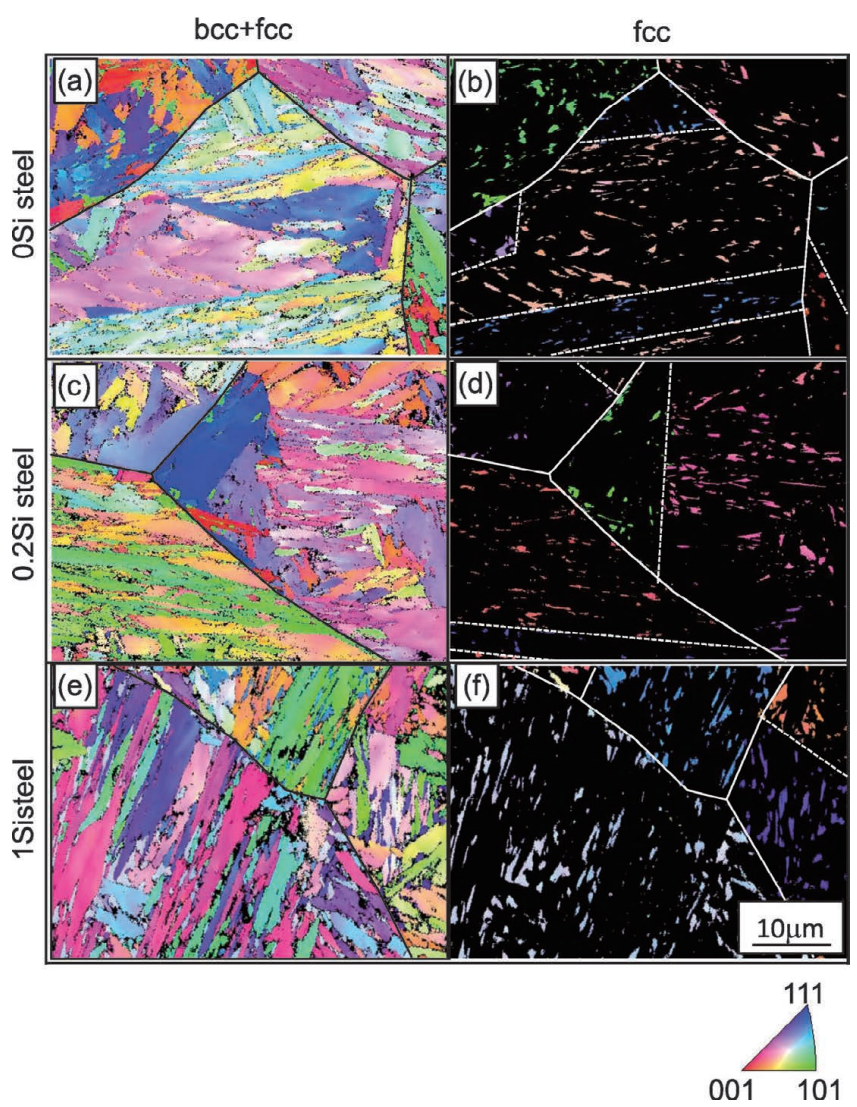

Fig. 5. Orientation imaging maps of $12 \mathrm{Cr}-0.12 \mathrm{C}-\mathrm{Si}$ steels with $723 \mathrm{~K}-0.6 \mathrm{ks}$ partitioning treatment. Martensite (bcc phase) and retained austenite (fcc phase) are simultaneously shown in $(a)(c)(e)$, while only retained austenite is shown in (b)(d)(f). 
sub-blocks, or laths. The size of the retained austenite grains is non-uniform, but enormously large grains are hardly observed in each specimen. The width of them is roughly $1.5 \mu \mathrm{m}$ or less, though the average size tends to be slightly enlarged with increasing silicon content. We also noticed that the volume fraction of retained austenite obtained by OIM system is small relative to the volume fraction measured by saturation magnetization (Fig. 4) in all specimens. This might be attributed to the fact that a portion of the retained austenite on the specimen surface transformed to martensite after polishing due to the relief of the constraints imposed by surrounding grains.

\subsection{Carbon Enrichment into Retained Austenite dur- ing Partitioning Treatment}

As shown in Figs. 4 and 5, fairly large amount of retained austenite was formed after Q\&P treatment despite the Mf temperatures of the steels is higher than room temperature. This result indicates that the enrichment of carbon into the retained austenite has taken place during the partitioning treatment. In order to demonstrate the carbon enrichment experimentally, lattice parameters of retained austenite are plotted as a function of partitioning time in Fig. 6. Since austenite lattice is expanded by interstitial elements, ${ }^{17)}$ the carbon enrichment causes an enlargement of lattice parameter of austenite phase. Therefore, from the change in lattice parameter shown in Fig. 6, it is indirectly suggested that the carbon concentration in retained austenite rapidly increases in the early stage of partitioning treatment, and reaches a maximum at around several hundred seconds, and then decreases again due to the precipitation of carbide (discussed later). It should be also noted that the silicon addition markedly retards the decrese of carbon concentration in retained austenite, especially in $1 \mathrm{Si}$ steel. This variation of carbon concentration well corresponds to that of austenite volume fraction (Fig. 4).

Before discussing the effect of silicon on the amount of retained austenite, the mechanism of carbon enrichment into austenite must be clarified. In the ideal Q\&P assuming the constrained carbon equilibrium (CCE), ${ }^{8,9,15,16)}$ the carbon enrichment is simply caused by the diffusion of carbon atoms from martensite to untransformed austenite until the chemical potential of carbon in both phases becomes identical. However, in most cases of Q\&P of low-alloy TRIP

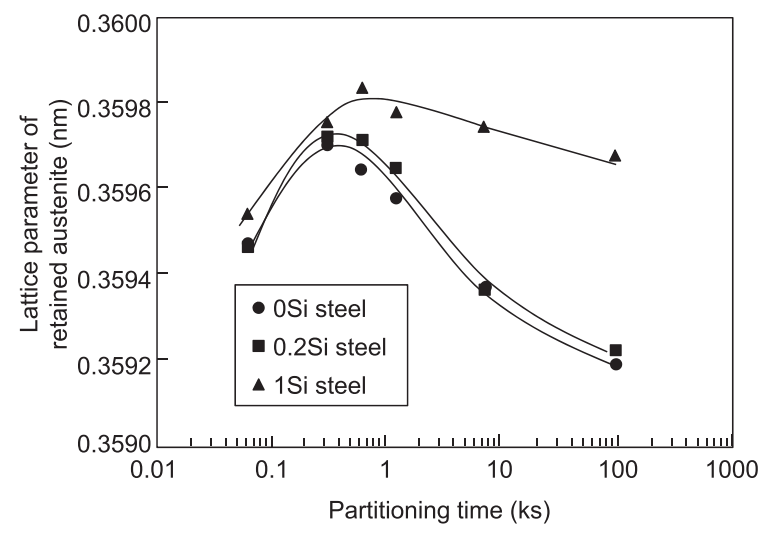

Fig. 6. Change in lattice parameter of retained austenite as function of partitioning time at partitioning temperature of $723 \mathrm{~K}$ in $12 \mathrm{Cr}-0.12 \mathrm{C}-\mathrm{Si}$ steels. steels, phase transformation from untransformed austenite to ferrite or bainite would take place during the partitioning treatment, ${ }^{11,18)}$ and the carbon enrichment is caused by the ejection from the transformed phase and it stops when the carbon concentration in austenite reaches $\mathrm{T}_{0}$ composition. ${ }^{5,19)}$ This means a CCE breakdown. On the other hand, a near CCE condition is realized in the case of martensitic stainless steel because the phase transformation during the partitioning treatment is markedly suppressed due to the large amount of chromium, as has already demonstrated for a $12 \mathrm{Cr}-0.12 \mathrm{C}-0.26 \mathrm{Si}$ steel. ${ }^{10)}$ In order to confirm this tendency for the specimens used in this study, the phase transformation behavior during the partitioning treatment was evaluated by means of dilatometry. Figure 7 represents the change in thermal dilatation (black lines) and temperature (gray lines) as a function of time. The specimen was quenched to each quenching temperature (QT) at a cooling rate of $0.33 \mathrm{~K} / \mathrm{s}$, and then heated to the partitioning temperature of $723 \mathrm{~K}$ and holding time: $1.8 \mathrm{ks}$. If the specimens caused bainitic transformation during the partitioning treatment, a significant volume expansion should appear at the treatment temperature; but the measured expansion is very slight in any specimens. The calculation of transformation fraction from the expansion ratio revealed that 0.5 through $0.8 \mathrm{vol} \%$ of austenite transformed to ferrite in $0.2 \mathrm{Si}$ and $1 \mathrm{Si}$ steels, while a little larger austenite approximately of 1.1 vol\% did in 0Si steel for the $0.6 \mathrm{ks}$ holding time (approximately the peak condition). Silicon seems to have some effect to retard phase transformation during partitioning treatment. In either case, the transformation fraction can be regarded as so small that the bainitic transformation hardly occurs in the case of partitioning treatment at $723 \mathrm{~K}$ in the martensitic stainless steels. This means a nearly ideal situation for Q\&P treatment is realized in this study, unlike the cases of low-alloy steels that easily cause bainitic transformation.

\subsection{Carbide Precipitation during Partitioning Treat- ment and Effect of Silicon on It}

In order to achieve carbon enrichment into untransformed austenite, the addition of silicon or aluminum is essential to suppress the carbide precipitation in low-alloy TRIP
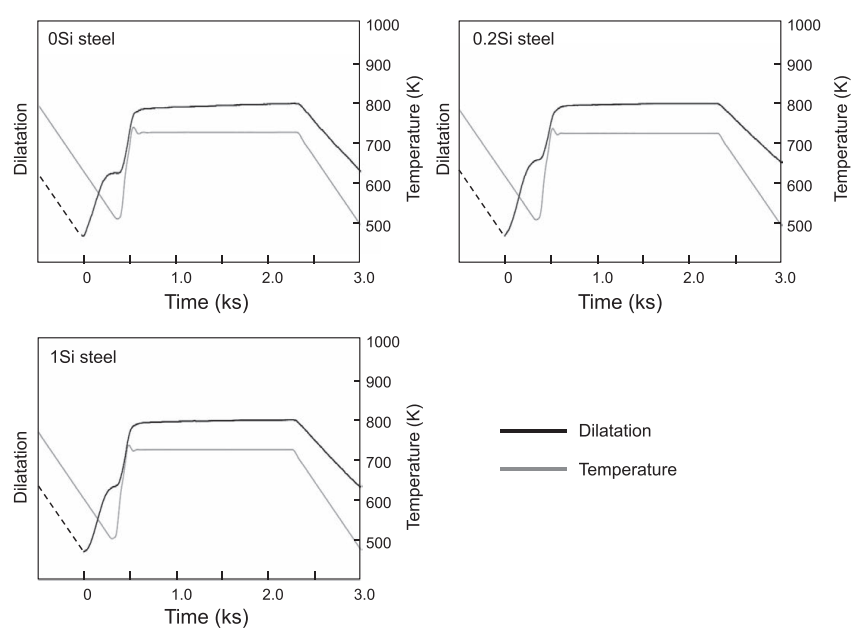

Fig. 7. Change in thermal dilatation and temperature as a function of time during Q\&P treatment. 
steels. ${ }^{6,11,12)}$ On the contrary, we reported that silicon addition is not necessarily required in the case of martensitic stainless steels owing to the chromium which retards the kinetics of carbide reaction in austenite. ${ }^{20)}$ However, it is a fact that the decrease in carbon concentration in the latter stage of partitioning treatment is remarkably delayed by silicon addition as shown in Fig. 6, and thus, it is possible that silicon addition may exhibit the suppression effect of carbide precipitation in martensitic stainless steel as well as low-alloy TRIP steel. Figures 8 and 9 represents TEM images of the $0.6 \mathrm{ks}$ partition-treated 0Si and 1Si steels, respectively. Tiny carbide particles are confirmed to exist on the retained austenite/martensite interfaces in each steel. Such a precipitation should have caused the depletion of solute carbon in austenite, leading to the decrease in the retained austenite after Q\&P treatment. The selected area diffraction (SAD) pattern revealed that these carbide particles are $\mathrm{M}_{3} \mathrm{C}$ type carbide, namely, cementite. It was also confirmed there was a tendency that its size becomes finer
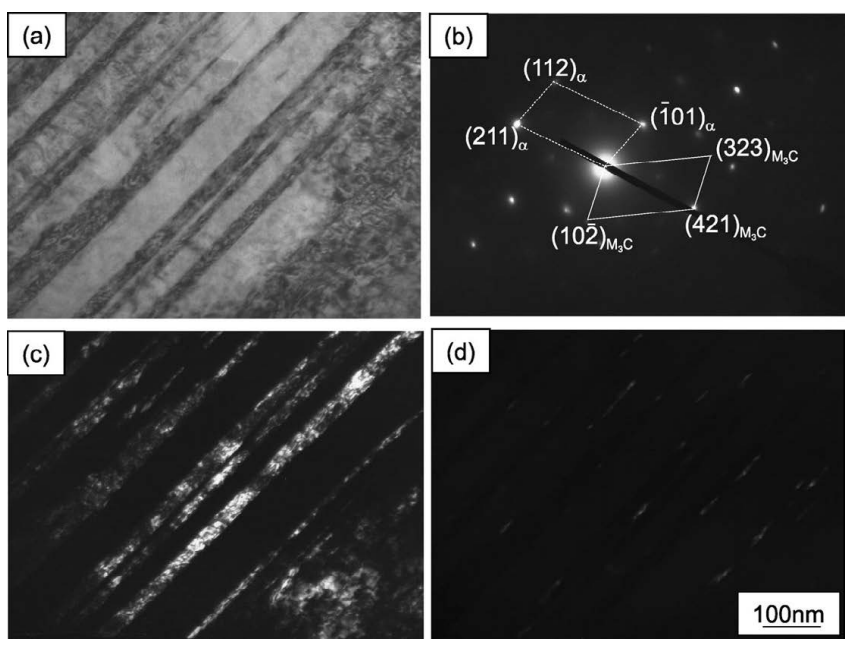

Fig. 8. TEM images and diffraction pattern for the $723 \mathrm{~K}-0.6 \mathrm{ks}$ partition-treated 0Si steel: (a) bright-field image, (b) corresponding SAD pattern, (c) dark-field image of retained austenite, (d) dark-field image of $\mathrm{M}_{3} \mathrm{C}$.
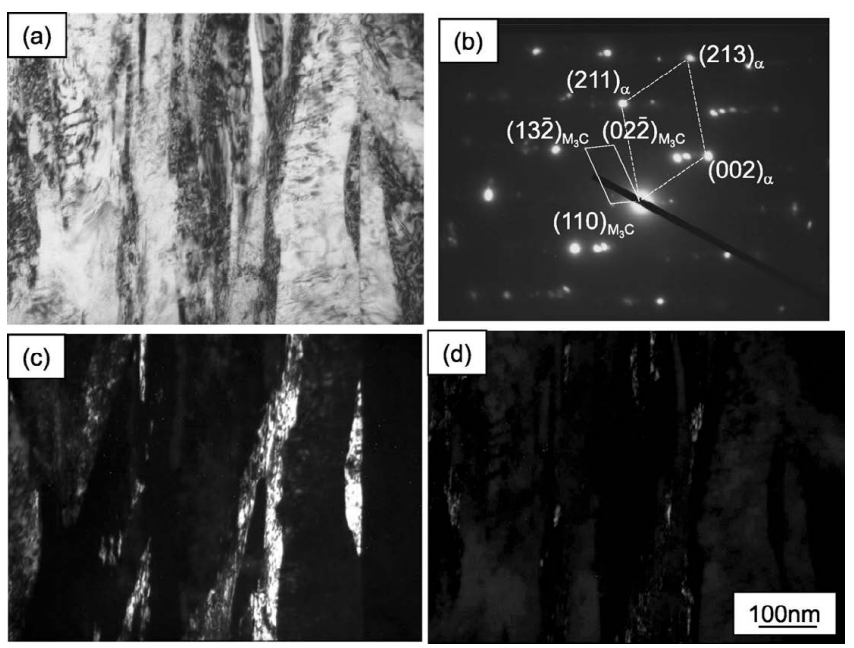

Fig. 9. TEM images and diffraction pattern for the $723 \mathrm{~K}-0.6 \mathrm{ks}$ partition-treated 1Si steel: (a) bright-field image, (b) corresponding SAD pattern, (c) dark-field image of retained austenite, (d) dark-field image of $\mathrm{M}_{3} \mathrm{C}$. and its volume fraction reduces as silicon content increases. In other words, the precipitation have been retarded with silicon addition. Besides, in the case of 0Si steel partitiontreated for $0.6 \mathrm{ks}$, even $\mathrm{M}_{7} \mathrm{C}_{3}$ type carbide, which is known to be formed in the next stage of tempering in high chromium steels, ${ }^{13)}$ appeared in the martensite matrix as shown in Fig. 10. As one of experimental methods to evaluate the rate of carbide precipitation during aging, differential scanning calorimeter, DSC, analysis is usually applied. ${ }^{21,22)}$ Figure 11 shows the DSC curves obtained during continuous heating at heating rate of $0.25 \mathrm{~K} / \mathrm{s}$ for as-quenched $0 \mathrm{Si}$ and $1 \mathrm{Si}$ steels. As a reference, the result of a low-alloy martensite ( $\mathrm{Fe}-0.15 \mathrm{C}-0 \mathrm{Si}-0.99 \mathrm{Mn})$ is also represented. It is known that the cementite precipitation takes place at around $573 \mathrm{~K}$ on tempering (stage 3) in carbon steel. ${ }^{21-23)}$ In the DSC curves, the clear peaks corresponding to the cementite precipitation are detected as pointed by the arrows, but the peak temperature is varied among the steels. Although the peak temperature of 0 $\mathrm{Si}$ steel is almost same that in low-alloy steel, the $1 \mathrm{Si}$ steel has a significantly higher peak temperature by as much as $70 \mathrm{~K}$. In addition, the amount of precipitate estimated from the heat generation is three times smaller in the $1 \mathrm{Si}$ steel $(0.075 \mathrm{~J} / \mathrm{g})$ than in the $0 \mathrm{Si}(0.21 \mathrm{~J} / \mathrm{g})$ steel.
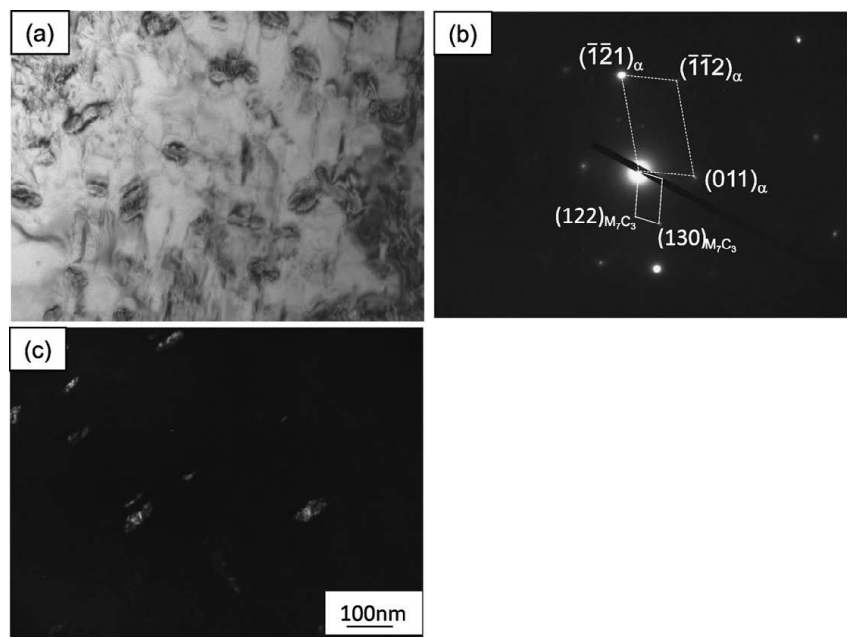

Fig. 10. TEM images and diffraction pattern for the $723 \mathrm{~K}-0.6 \mathrm{ks}$ partition-treated 0Si steel: (a) bright-field image, (b) corresponding SAD pattern, (c) dark-field image of $\mathrm{M}_{7} \mathrm{C}_{3}$.

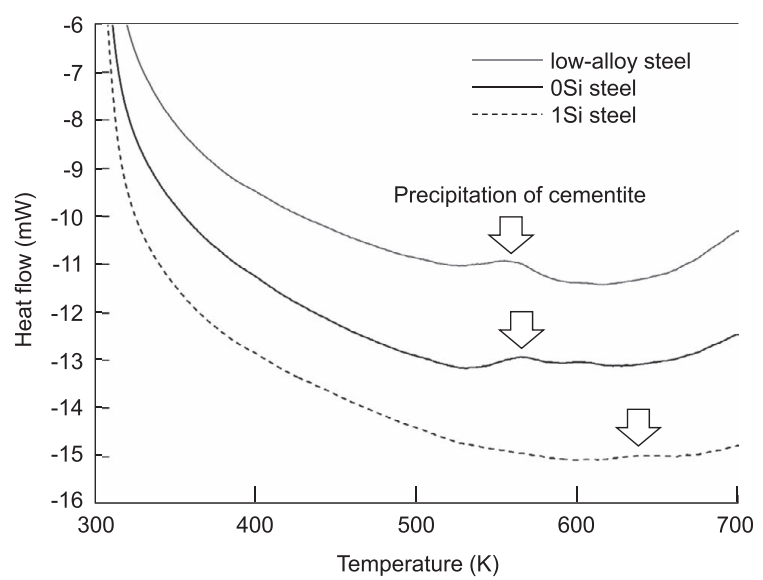

Fig. 11. The DSC curves obtained during continuous heating at heating rate of $0.25 \mathrm{~K} / \mathrm{s}$ for as-quenched low-alloy steel, 0Si steel and 1Si steel. 
This result suggests that silicon addition suppresses the precipitation of cementite during tempering in $12 \mathrm{Cr}$ steel. But it should be noted that the behavior detected here is not for precipitation in austenite but in martensite. Since the amount of retained austenite corresponds to carbon concentration in retained austenite, the precipitation rate in austenite, particularly at grain boundary, should be more important. Nevertheless, it is sufficient data for dictating the important nature of silicon that suppresses the cementite precipitation at elevated temperature in $12 \mathrm{Cr}$ steels similarly to low-alloy carbon steels.

\subsection{Mechanical Property of Q\&P-treated Martensitic Stainless Steels Containing Silicon}

Tensile tests were performed for the Q\&P-treated specimens to evaluate the effect of the increased amount of retained austenite in the $\mathrm{Si}$-added low-carbon martensitic stainless steels. The tensile strength and total elongation of all Q\&P-treated steels are plotted in Fig. 12. For comparison, the data of conventional quenching and tempering (Q\&T) is also included in the same figure. The condition of heat treatment and the volume fraction of austenite for each specimen are listed in Table 2. It is clearly shown that the Q\&P steels express an improved strength-ductility balance compared with Q\&T steels. In particular, silicon addition has a great influence on the tensile properties of Q\&P steels; the strength-ductility balance of $1 \mathrm{Si}$ steel is much more

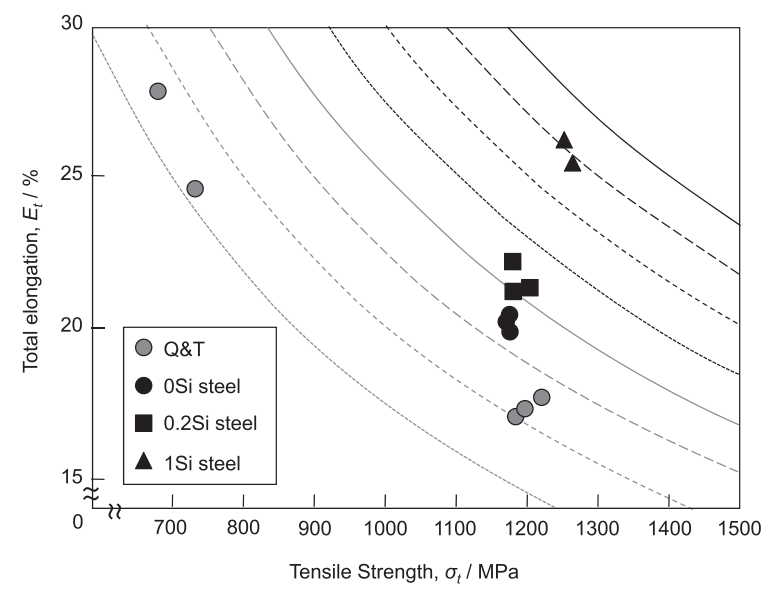

Fig. 12. Strength-ductility balance of $12 \mathrm{Cr}-0.1 \mathrm{C}$ steels with Q\&P and Q\&T.

Table 2. Heat treatment condition and volume fraction of austenite for tensile-tested specimens.

\begin{tabular}{|c|c|c|c|}
\hline \multirow{2}{*}{ steel } & \multicolumn{2}{|c|}{ Heat treatment } & $\begin{array}{c}\text { The volume fraction } \\
\text { of austenite (vol\%) }\end{array}$ \\
\hline 0Si steel & Q\&P & $723 \mathrm{~K}-0.6 \mathrm{ks}$ & 12.7 \\
\hline \multirow{3}{*}{$0.2 \mathrm{Si}$ steel } & \multirow{2}{*}{ Q\&T } & $723 \mathrm{~K}-0.6 \mathrm{ks}$ & 13.7 \\
\cline { 3 - 4 } & & $723 \mathrm{~K}-0.12 \mathrm{ks}$ & - \\
\cline { 3 - 4 } & & $873 \mathrm{~K}-3.6 \mathrm{ks}$ & - \\
\cline { 3 - 4 } & & $923 \mathrm{~K}-3.6 \mathrm{ks}$ & - \\
\hline 1Si steel & Q\&P & $723 \mathrm{~K}-0.6 \mathrm{ks}$ & 15.2 \\
\hline
\end{tabular}

excellent than others. From the results, it is suggested that increasing retained austenite and its stability by silicon addition is very effective for upgrading the mechanical properties of Q\&P-treated 12Cr martensitic stainless steel.

\section{Conclusions}

(1) Quenching and partitioning (Q\&P) treatment is effective for forming retained austenite in $12 \mathrm{Cr}$ low-carbon martensitic stainless steel. Since the phase transformation of austenite at elevated temperature is markedly suppressed by the chromium, the nearly ideal constrained carbon equilibrium $(\mathrm{CCE})$ condition seems to hold during the partitioning treatment.

(2) Silicon addition to the martensitic stainless steels up to $1 \mathrm{mass} \%$ leads to a remarkable retardation of cementite precipitation during the partitioning treatment. As a result, the amount of retained austenite is significantly increased, and besides, the thermal stability of the retained austenite is also enhanced.

(3) In comparison with conventional quench-and-tempered steel, the Q\&P-treated martensitic stainless steels has an improved strength-ductility balance. With increasing silicon content, the mechanical property is further improved through the increase in the amount of retained austenite.

\section{REFERENCES}

1) F. K. Bloom: Corrosion, 9 (1953), 56.

2) K. J. Irvine, D. J. Crowe and F. B. Pickering: J. Iron Steel Inst., 195 (1960), 43.

3) E. A. Little, D. R. Harries, F. B. Pikering and S. R. Keown: Met. Technol., 4 (1977), 205.

4) O. Matsumura, Y. Sakuma and H. Takechi: ISIJ Int., 27 (1987), 570.

5) M. Takahashi, H. Yoshida and S. Hiwatashi: Proc. Int. Conf. TRIPAided High Strength Ferrous Alloys, ed. by B.C. De Cooman, Mainz, Aachen, (2002), 103.

6) H. C. Chen, H. Era and M. Shimizu: Metall. Trans. A, 20A (1989), 437.

7) B. C. De Cooman: Curr. Opin. Solid State Mater. Sci., 8 (2004), 285.

8) J. Speer, D. K. Matlock, B. C. De Cooman and J. G. Schroth: Acta Mater., 51 (2003), 2611.

9) J. G. Speer, D.V. Edmonds, F.C. Rizzo and D. K. Matlock: Curr. Opin. Solid State Mater. Sci., 8 (2004), 219.

10) T. Tsuchiyama, J. Tobata, T. Tao, N. Nakada and S. Takaki: Mater. Sci. Eng. A, 532 (2012), 585.

11) M. J. Santofimia, T. Nguyen-Minh, L. Zhao, R. Petrov, I. Sabirov and J. Sietsma: Mater. Sci. Eng. A, 527A (2010), 6429.

12) E. De Moor, S. Lacroix, L. Samek, J. Penning and J. G. Speer: 3rd Int. Conf. on Advanced Structural Steels, Gyeongju, Korea, (2006).

13) T. Sato: Bull. Jpn. Inst. Met., 7 (1968), 363.

14) T. Hara, H. Goto and S. Takaki: J. Jpn. Soc. Heat Treat., 36 (1996), 322.

15) M. Hillert and J. Agran: Scr. Mater., 50 (2004), 697.

16) M. Hillert and J. Agran: Scr. Mater., 52 (2005), 87.

17) M. Onink, C. M. Brakman, F. D. Tichelaar, E. J. Mittemeijer, S. van der Zwaag, J. H. Root and N. B. Konyer: Scr. Metall., 29 (1993), 1011.

18) H. Y. Li, X. W. Lu, W. J. Li and X. J. Jin: Metall. Mater. Trans. A, 41A (2010), 1284.

19) M. Takahashi and H. K. D. Bhadeshia: Mater. Trans., JIM, 32 (1991), 689.

20) T. Suzuki, Y. Ono, G. Miyamoto and T. Furuhara: ISIJ Int., 50 (2010), 1467.

21) P. V. Morra, A. J. Böttger and E. J. Mittemeijer: J. Thermal Anal. Calorimetry, 64 (2001), 905.

22) M. J. Van Genderen, M. Isac, A. Böttger and E. J. Mittemeijer: Metall. Trans. A, 28A (1997), 545.

23) R. W. K. Honeycombe and H. K. D. H. Bhadeshia: STEELS Microstructure and Properties, 2nd ed., Edward Arnold, London, (1995), 174. 